\title{
Agitation, CTCAE 5.0
}

National Cancer Institute

\section{Source}

National Cancer Institute. Agitation, CT CAE 5.0. NCI Thesaurus. Code C146777.

A disorder characterized by a state of restlessness associated with unpleasant feelings of irritability and tension. 